Cahiers $d u$ MONDE RUSSE

\section{Cahiers du monde russe}

Russie - Empire russe - Union soviétique et États indépendants

$51 / 4 \mid 2010$

Sciences humaines et sociales en Russie à l'Âge d'argent

\title{
Stefan Lemny, Les Cantemir
}

\section{Rodolphe Baudin}

\section{(2) OpenEdition}

Journals

Édition électronique

URL : https://journals.openedition.org/monderusse/7362

DOI : 10.4000/monderusse.7362

ISSN : 1777-5388

Éditeur

Éditions de l'EHESS

Édition imprimée

Date de publication : 25 novembre 2010

Pagination : 673-675

ISBN : 978-2-7132-2316-7

ISSN : $1252-6576$

Référence électronique

Rodolphe Baudin, «Stefan Lemny, Les Cantemir », Cahiers du monde russe [En ligne], 51/4 | 2010, mis en ligne le 09 décembre 2011, consulté le 02 septembre 2022. URL : http://journals.openedition.org/ monderusse/7362 ; DOI : https://doi.org/10.4000/monderusse.7362

Ce document a été généré automatiquement le 2 septembre 2022

Tous droits réservés 


\title{
Stefan Lemny, Les Cantemir
}

\author{
Rodolphe Baudin
}

\section{RÉFÉRENCE}

\section{Stefan LEMNY, Les Cantemir. L'aventure européenne d'une famille princière au} XVIII $^{\mathrm{e}}$ siècle. Bruxelles : Complexe, 2009, 368 p.

1 Spécialiste reconnu de l'histoire de la Roumanie et du XVIII siècle français, Stefan Lemny s'intéresse dans son dernier ouvrage aux deux Cantemir : le père, Demetrius, historien, musicien et prince de Moldavie, ayant fait alliance avec Pierre le Grand dans l'espoir de voir son pays libéré de la domination turque ; et le fils, Antiochus, ambassadeur d'Anna Ivanovna puis d'Élisabeth Petrovna, d'abord à Londres, puis à Paris, mais également écrivain, bien connu en Russie pour ses satires, et pour son rôle dans l'introduction du classicisme dans la littérature du XVIII ${ }^{\mathrm{e}}$ siècle.

Double biographie, l'ouvrage de Stefan Lemny est découpé en deux grandes parties, ellesmêmes subdivisées en chapitres relatant les diverses périodes de la vie des deux hommes et/ou leurs divers centres d'intérêt et activités intellectuelles. À cette double biographie s'en ajoute d'ailleurs une troisième en filigrane, celle du père de Demetrius et grand-père d'Antiochus, Constantin, boyard moldave monté sur le trône de son pays et fondateur à ce titre de la dynastie.

3 L'ajout de ce troisième personnage permet de développer la problématique centrale du livre : habile mais inculte, Constantin fonde une dynastie dont le seul prestige est celui des armes. Son fils et son petit-fils auront à cœur de compenser ce déficit de capital symbolique en y ajoutant le prestige des lettres. Heureux tous deux dans cette aventure, ils le furent toutefois beaucoup moins en politique. Le père, Demetrius, ne régna ainsi que quelques mois. Quant au fils Antiochus, il se contenta d'une carrière diplomatique, certes réussie, au service de la Russie.

4 La deuxième problématique de l'ouvrage de Stefan Lemny est celle de l'interculturalité et de la manière dont les deux Cantemir la gérèrent, notamment en remplissant la fonction de passeurs de cultures. Demetrius, ainsi, faisait coexister harmonieusement sa 
culture moldave orthodoxe et la culture de ses souverains turcs, dont il connaissait la langue, la religion et la musique. À ce titre, il servit de passeur, tout d'abord en mettant ses connaissances sur l'Empire ottoman au service de Pierre le Grand, puis en rédigeant des ouvrages sur l'histoire de la Porte, notamment son Histoire de l'Empire ottoman, que les efforts de son fils feront connaître dans l'Europe entière. Le fils, Moldave russifié, contribua d'abord à importer en Russie le classicisme français avec ses satires, puis vécut en Europe, où il côtoya savants, musiciens et écrivains, dont il traduisit vers le russe les œuvres, notamment les Entretiens sur la pluralité des mondes de Fontenelle.

L'évolution de la famille Cantemir, ainsi, les voit passer en deux générations de boyard inculte à interlocuteur de Voltaire et Montesquieu. Cette évolution se double d'un périple géographique, de la Moldavie sous souveraineté turque à Londres et Paris. Et c'est là la troisième idée développée par l'ouvrage : en décrivant l'arc menant d'Istanbul à Paris, Stefan Lemny interroge la géographie culturelle de l'Europe des Lumières, en la décentrant quelque peu: Istanbul y trouve sa place, de même que Moscou et SaintPétersbourg, considérées, depuis la Porte, comme une première étape européenne, et non, comme depuis Paris, comme une première étape asiatique.

Bâti sur ces trois problématiques (construction d'une dynastie, fonctions des passeurs culturels, redéfinition de la géographie intellectuelle des Lumières), l'ouvrage de Stefan Lemny est d'une lecture enrichissante. On ne peut qu'être impressionné par l'ampleur de l'information de l'auteur, dont témoigne indirectement la bibliographie en cinq langues (français, anglais, russe, roumain et allemand) qui clôt l'ouvrage. Le tableau donné par l'auteur de la vie de Demetrius et du milieu intellectuel orthodoxe d'Istanbul est passionnant. En regard, la partie de l'ouvrage consacrée à Antiochus parait un peu plus pâle, même si ceci s'explique sans doute parce qu'il y est fait référence à des événements et des réseaux sociaux bien mieux connus du dix-huitiémiste « classique ».

7 À cette remarque, on peut en ajouter quelques autres. On regrettera d'abord le manque de définitions. Tout lecteur n'étant pas spécialiste du sujet traité, on aurait souhaité que Stefan Lemny explique les termes renvoyant aux réalités politiques moldave et ottomane du XVIII siècle ("drogman », p. 73 ; « hasnadar», p. 91 ; « hospodar », p. 289). De même, on peut déplorer la présence de quelques fautes factuelles ou d'interprétation. Ainsi la mort de Pierre $\mathrm{I}^{\mathrm{er}}$ est datée tantôt de 1724 (p. 177), tantôt du 8 février 1725 (p. 182), tantôt du 26 janvier 1725 (p. 190). La première datation est erronée. Quant aux deux autres, elles correspondent respectivement à la date exacte dans le nouveau style et dans l'ancien, entre lesquels l'auteur ne semble pas choisir. Le domaine de Černaja Grjaz', racheté par Catherine II à la famille Cantemir en 1775, accueillit le palais de Caricyno, et non de Carskoe Selo (p. 113). Ensuite il est inexact, dans le système du classicisme, de définir l'ode comme un genre «mineur» (p. 193, 271). De même, il ne convient pas de s'étonner de l'absence, dans la bibliothèque d'Antiochus, des œuvres de Shakespeare et de Rabelais (p.265). En effet, cette bibliothèque reflète les goûts des lecteurs des Lumières. Or, ni Shakespeare, critiqué par les tenants du classicisme pour son manque de règles, ni Rabelais, rarement publié et seulement dans des éditions "policées", ne correspondent à ce goût, en tout cas dans les années 1730-1740. Enfin, on pourra regretter que l'auteur, dont l'approche est parfaitement moderne dans les domaines de l'analyse des réseaux de sociabilité, ou des stratégies d'ascension sociale des Cantemir, emprunte des jugements ou cède parfois à des considérations quelque peu obsolètes. Ainsi eût-il sans doute été préférable de traiter avec distance le jugement de Belinskij sur Antiochus, selon lequel le poète «a uni la littérature à la vie» (p. 276). De même, l'évocation par 
Stefan Lemny de traits de caractère des personnages évoqués sur la base de la description de tableaux (p. 42, 302) paraît très subjective, et n'accorde pas toujours l'importance qui lui est due au poids des codes picturaux présidant à la représentation. Enfin, et pour terminer, l'ouvrage présente malheureusement un nombre important de coquilles que l'on peut souhaiter voir disparaître lors d'une éventuelle réédition.

8 Ces quelques remarques faites, il faut rendre hommage à l'auteur. Son travail est une somme d'érudition remarquable sur un sujet mal connu, qui articule intelligemment, à travers les trois problématiques évoquées plus haut, la biographie d'acteurs majeurs des Lumières russes à leur début. Enfin, et ce n'est pas son moindre mérite, le livre de Stefan Lemny replace le talent reconnu d'Antiochus dans la généalogie fascinante et bien moins connue, en tout cas du lecteur francophone, de la famille Cantemir. 